\title{
Inhibition of Adult Neurogenesis by Inducible and Targeted Deletion of ERK5 Mitogen-Activated Protein Kinase Specifically in Adult Neurogenic Regions Impairs Contextual Fear Extinction and Remote Fear Memory
}

\author{
Yung-Wei Pan, ${ }^{1}$ Guy C. K. Chan, ${ }^{2}$ Chay T. Kuo, ${ }^{4}$ Daniel R. Storm, ${ }^{2}$ and Zhengui Xia ${ }^{1,3}$ \\ ${ }^{1}$ Graduate Program in Molecular and Cellular Biology, ${ }^{2}$ Department of Pharmacology, and ${ }^{3}$ Toxicology Program, Department of Environmental and \\ Occupational Health Sciences, University of Washington, Seattle, Washington 98195, and ${ }^{4}$ Departments of Cell Biology and Pediatrics, Duke University \\ Medical Center, Durham, North Carolina 27710
}

\begin{abstract}
Although there is evidence suggesting that adult neurogenesis may contribute to hippocampus-dependent memory, signaling mechanisms responsible for adult hippocampal neurogenesis are not well characterized. Here we report that ERK5 mitogenactivated protein kinase is specifically expressed in the neurogenic regions of the adult mouse brain. The inducible and conditional knock-out (icK0) of erk5 specifically in neural progenitors of the adult mouse brain attenuated adult hippocampal neurogenesis. It also caused deficits in several forms of hippocampus-dependent memory, including contextual fear conditioning generated by a weak footshock. The ERK5 icK0 mice were also deficient in contextual fear extinction and reversal of Morris water maze spatial learning and memory, suggesting that adult neurogenesis plays an important role in hippocampus-dependent learning flexibility. Furthermore, our data suggest a critical role for ERK5-mediated adult neurogenesis in pattern separation, a form of dentate gyrus-dependent spatial learning and memory. Moreover, ERK5 icKO mice have no memory $21 \mathrm{~d}$ after training in the passive avoidance test, suggesting a pivotal role for adult hippocampal neurogenesis in the expression of remote memory. Together, our results implicate ERK5 as a novel signaling molecule regulating adult neurogenesis and provide strong evidence that adult neurogenesis is critical for several forms of hippocampus-dependent memory formation, including fear extinction, and for the expression of remote memory.
\end{abstract}

\section{Introduction}

The mammalian brain has the remarkable capacity to process and store information. Since deficits in memory are prominent features of aging and many mental disorders, there is intense interest in the molecular and cellular basis of learning and memory. Several signal transduction pathways in neurons, including calcium, cAMP, and ERK1/2 mitogen-activated protein (MAP) kinase,

Received Dec. 7, 2011; revised Feb. 17, 2012; accepted March 6, 2012.

Author contributions: Y.-W.P. and Z.X. designed research; Y.-W.P. and G.C.K.C. performed research; C.T.K. contributed unpublished reagents/analytic tools; Y.-W.P., G.C.K.C., D.R.S., and Z.X. analyzed data; Y.-W.P., D.R.S., and Z.X. wrote the paper.

The authors declare no competing financial interests.

This work was supported by the National Institutes of Health [Grants NS20498 (D.R.S.) and T32HD007183 and F31DC011216 (Y.-W.P.)] and the Sheldon D. Murphy Endowed Chair in Toxicology (Z.X.) and was facilitated by National Institute of Child Health and Human Development Grant P30 HD02274. The funders had no role in study design, data collection and analysis, decision to publish, or preparation of this manuscript. We thank Dr. Cathy Tournier (University of Manchester, Manchester, UK) and Dr. Bradford C. Berk (University of Rochester, Rochester, NY) for transfer of ERK5 ${ }^{\text {loxP/loxP }}$ mice, Dr. Toby Cole and members of the Storm and Xia laboratories for technical assistance on behavior tests, Dr. Tom Burbacher for using his facility for water maze tests, Glen MacDonald for technical assistance on confocal imaging, and members of the Xia laboratory for critical reading of this manuscript.

Correspondence should be addressed to Dr. Zhengui Xia, Toxicology Program, Department of Environmental and Occupational Health Sciences, Box 357234, University of Washington, Seattle, Washington, 98195. E-mail: zxia@u.washington.edu.

DOI:10.1523/JNEUROSCI.6076-11.2012

Copyright $\odot 2012$ the authors $\quad 0270-6474 / 12 / 326444-12 \$ 15.00 / 0$ have been implicated in the regulation of memory formation (Silva et al., 1992; Yin et al., 1994; Wu et al., 1995; Atkins et al., 1998; Taubenfeld et al., 1999; Wong et al., 1999; Athos et al., 2002). Interestingly, recent studies support the idea that hippocampus-dependent memory may also depend on newly generated neurons in the adult dentate gyrus.

Adult neurogenesis occurs in the subgranular zone (SGZ) of the dentate gyrus and the subventricular zone (SVZ) along the lateral ventricles in mammalian brains (Altman and Das, 1965; Alvarez-Buylla et al., 1988). Adult-born neurons in the dentate gyrus functionally integrate into the hippocampal circuitry (Ming and Song, 2005), suggesting a role in neuroplasticity. Hippocampus-dependent, but not hippocampus-independent, learning increases adult neurogenesis in the dentate gyrus (Leuner et al., 2004). Furthermore, training for hippocampusdependent memory selectively adds or removes adult-born neurons depending on the birthdate of the neurons relative to training (Döbrössy et al., 2003; Dupret et al., 2007). These data support the hypothesis that newly generated adult-born neurons of the dentate gyrus contribute to hippocampus-dependent memory (Leuner and Gould, 2010). Despite these exciting discoveries, signaling mechanisms regulating adult neurogenesis are not fully understood. Additionally, although a number of studies 


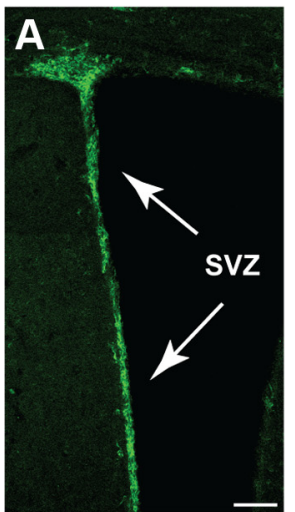

ERK5 Protein

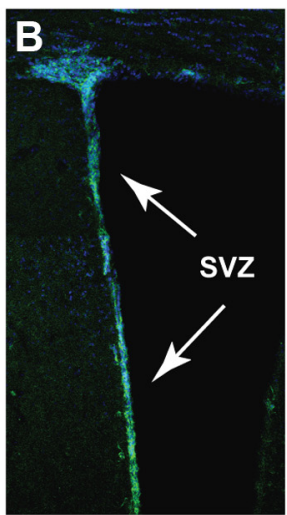

ERK5 / Hoechst
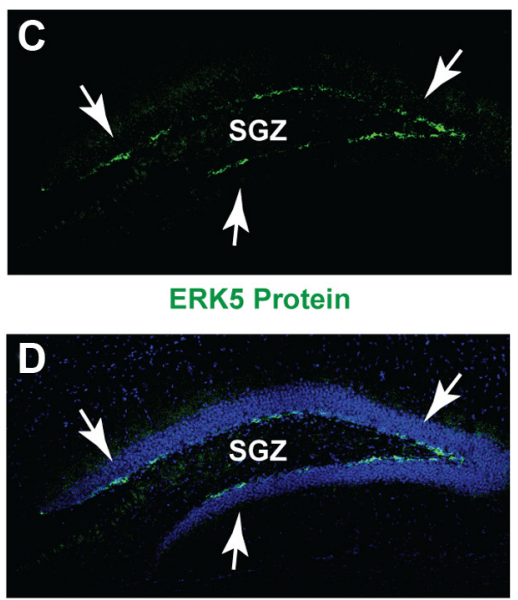

ERK5 / Hoechst

Striatum

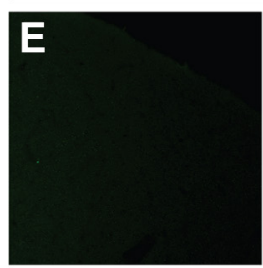

ERK5 Protein

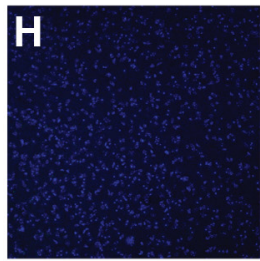

ERK5 / Hoechst
ERK5 Protein
Cortex

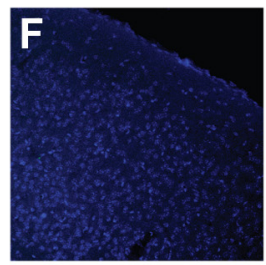

ERK5 / Hoechst

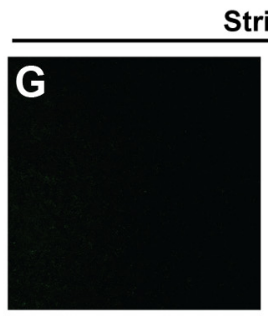

ERK5 Protein
Figure 1. ERK5 is specifically expressed in the adult neurogenic regions in the mouse brain. Immunostaining of coronal sections of adult mouse brain tissue shows ERK5 protein expression (green) primarily in the SVZ $(\boldsymbol{A}, \boldsymbol{B})$ and SGZ $(\boldsymbol{C}, \boldsymbol{D})$ of the hippocampus but is absent in other brain regions such as the cortex $(\boldsymbol{E}, \boldsymbol{F})$ and striatum $(\boldsymbol{G}, \boldsymbol{H})$. Hoechst staining (blue) was used to identify all cell nuclei $(\boldsymbol{B}, \boldsymbol{D}, \boldsymbol{F}, \boldsymbol{H})$. Scale bar, $100 \mu \mathrm{m}$.

have attempted to assess the role of adult neurogenesis in hippocampus-dependent memory, data from different studies are contradictory, and the function of adult-born neurons in the dentate gyrus remains controversial (Deng et al., 2010).

ERK5 is a member of the MAP kinase family that includes ERK1/2 (Lee et al., 1995; Zhou et al., 1995). Neurotrophin activation of ERK5 promotes the survival of newborn neurons during embryonic development (Cavanaugh et al., 2001; Watson et al., 2001; Liu et al., 2003; Shalizi et al., 2003; Y. Wang et al., 2006; Finegan et al., 2009). ERK5 also specifies cortical stem/progenitor cells toward a neuronal lineage during development by phosphorylating and modulating the activity of neurogenin 1 (Liu et al., 2006; Cundiff et al., 2009). ERK5 expression in the brain is high during early embryonic development but declines as the brain matures (Liu et al., 2003). It is generally thought that ERK5 is not expressed in the adult brain (Di Benedetto et al., 2007). However, on closer examination, we discovered selective ERK5 expression in the adult neurogenic regions, the SGZ and SVZ. This pattern of expression is unique and suggests an important role for ERK5 in the regulation of adult neurogenesis.

Here, we generated ERK5 inducible and conditional knockout (icKO) mice to delete erk5 specifically in the neurogenic regions of the adult brain. This mouse strain provides a unique and powerful tool to investigate the role of ERK5 in adult neurogenesis and to delineate the relationship between adult neurogenesis and hippocampus-dependent learning and memory.

\section{Materials and Methods}

Animals. Nestin-CreER ${ }^{\mathrm{TM}}$ (Kuo et al., 2006) and ERK5 ${ }^{\text {loxP/loxP }}$ (Wang et al., 2005) mice were crossed to yield Nestin-CreER ${ }^{\mathrm{TM}} / \mathrm{ERK}^{\text {loxP/+ }}$ ani- mals. Nestin-CreER ${ }^{\mathrm{TM}} / \mathrm{ERK} 5^{\text {loxP/+ }}$ mice were further crossed with $\mathrm{ERK} 5^{\text {loxP/loxP }}$ mice to yield homozygous Nestin-CreER ${ }^{\mathrm{TM}} / \mathrm{ERK}^{\text {lox/P/ }}$ loxP animals, which were used for experimental breeding. All animal experiments were performed with identically treated and handled littermate controls. Animals were housed under standard conditions ( $12 \mathrm{~h}$ light/dark cycle) with food and water provided ad libitum, except where indicated. All experimental procedures were approved by the University of Washington Institutional Animal Care and Use Committee.

Reagents. The following primary antibodies and dilutions were used for immunohistochemistry: rat monoclonal anti-BrdU (1:500, $\mathrm{AbD}$; Serotec); mouse monoclonal anti-NeuN (1:500; Millipore); and goat polyclonal antiNeuroD (1:200; Santa Cruz Biotechnology). Rabbit polyclonal ERK5 antibody (1:500) was generated previously (Cavanaugh et al., 2001) and affinity purified using recombinant MBPERK5 protein.

$B r d U$ and tamoxifen administration. Mice received $100 \mathrm{mg} / \mathrm{kg}$ BrdU (Sigma-Aldrich) by intraperitoneal injection five times (every $2 \mathrm{~h}$ for $10 \mathrm{~h}$ ) in $1 \mathrm{~d}$ and were killed 3 weeks later to identify BrdU-retaining, adult-born cells. Tamoxifen (Sigma-Aldrich) was made fresh daily and dissolved in $2 \%$ glacial acetic acid in corn oil solution (Sigma). To activate Cre-mediated recombination, $5 \mathrm{mg}$ of prewarmed tamoxifen was administered orally to 10 - to 12 -week-old male mice daily for $7 \mathrm{~d}$ (for studies presented in Figs. 2, 3A-F,M) or once per day for $4 \mathrm{~d}$ in each cycle, for three cycles with 2 week intercycle intervals (for studies presented in Figs. $3 G-M, 4-10$ ).

Immunohistochemistry. Mice were perfused intracardially with icecold solutions of $20 \mathrm{ml}$ of PBS, followed by $20 \mathrm{ml}$ of $4 \%$ paraformaldehyde (PFA) in PBS. Brains were harvested and postfixed in 4\% PFA/PBS overnight at $4^{\circ} \mathrm{C}$, followed by $30 \%(\mathrm{w} / \mathrm{v})$ sucrose in PBS solution at $4^{\circ} \mathrm{C}$ until brains sunk. Immediately after sucrose embedding, brains were frozen at $-80^{\circ} \mathrm{C}$ until immunohistochemistry (IHC) processing. IHC was performed on $30-\mu \mathrm{m}$-thick coronal brain sections using a freefloating antibody staining method. Briefly, brain sections were washed four times for 10 min with $0.1 \mathrm{M}$ PBS, $\mathrm{pH}$ 7.4, followed by three times for 10 min with PBST (PBS plus $0.25 \%$ Triton X-100). Brain slices were then incubated in blocking buffer (PBST plus $0.1 \%$ bovine serum albumin plus $10 \%$ normal serum) for $>2 \mathrm{~h}$ at room temperature. Where IHC for $\mathrm{BrdU}$ visualization was required, brain sections were washed four times for $10 \mathrm{~min}$ with $0.1 \mathrm{M} \mathrm{PBS}, \mathrm{pH} 7.4$; subjected to $\mathrm{HCl}$ treatment by sequential incubation in water for $5 \mathrm{~min}$, in ice-cold $1 \mathrm{~N} \mathrm{HCl}$ for $10 \mathrm{~min}$, and in $2 \mathrm{~N} \mathrm{HCl}$ for $30 \mathrm{~min}$ at $37^{\circ} \mathrm{C}$; and, finally, neutralized by rinsing two times for $5 \mathrm{~min}$ in $0.5 \mathrm{M}$ borate buffer, $\mathrm{pH}$ 8.5. This was followed by PBST washes and blocking as stated above. Brain sections were incubated with primary antibodies for $48-60 \mathrm{~h}$ at $4^{\circ} \mathrm{C}$ on a platform shaker. Brain sections were washed in PBST four times for 10 min after primary antibody incubation and incubated with secondary antibodies conjugated with Alexa Fluor dyes (1:500 dilution; Invitrogen) in blocking buffer overnight at $4^{\circ} \mathrm{C}$ on a platform shaker. Brain sections were then washed four times for $10 \mathrm{~min}$ in PBST, incubated with $2.5 \mu \mathrm{g} / \mathrm{ml}$ Hoechst 33342 (Invitrogen) for $30 \mathrm{~min}$, and washed three times for $5 \mathrm{~min}$ with PBST. Unless otherwise stated, all IHC procedures were performed at room temperature. Brain sections were then mounted on gelatin-coated Superfrost plus slides (VWR) with anti-fade Aqua Poly/Mount (Polysciences).

Confocal imaging and analysis. All images were captured with an Olympus Fluoview-1000 laser scanning confocal microscope with numerical aperture (NA) $0.75,20 \times$ lens; NA 1.3, $40 \times$ oil lens; or NA 1.35, $60 \times$ oil-immersion lens. Optical $Z$-sections $(0.5-1 \mu \mathrm{m})$ were collected 
and processed using ImageJ software (NIH). Images were uniformly adjusted for color, brightness, and contrast with Adobe Photoshop CS4 (Adobe Systems).

Quantification of immunostained cells. One in every eight serial brain slices through the entire rostrocaudal extent of the granule cell layer was immunostained for each marker. Immunopositive cells were analyzed and quantified using a modified unbiased stereology technique (West et al., 1991; Kempermann et al., 1997; Malberg et al., 2000) by confocal analysis of the granule cell layer of one-half of the brain with the experimenter blinded to treatment conditions. Resulting numbers were multiplied by 8 to obtain an estimated total number of cells per dentate gyrus. For colocalization analysis, cells were analyzed per marker combination using confocal microscopy. At least 50 immunopositive cells were selected randomly, and the presence of overlapping fluorescent signals in a $Z$-series stack of a single cell was considered to be a double-positive cell.

Open-field test and habituation. Mice were placed in a 10 (width) $\times 10$ (depth) $\times 16$ (height) inch TruScan Photo Beam Tracking arena with clear sidewalls and infrared beams spaced 0.6 inches apart, providing a spatial resolution of 0.3 inch (Coulbourn Instruments). Mice were not prehabituated to the arena to permit baseline locomotor activity and anxiety level analysis. Twenty minutes of free exploratory time were allotted per mouse on day 1 for the open-field test. Data were collected and analyzed using TruScan 2.02 software (Coulbourn Instruments). To analyze habituation in the open field, mice were placed in the same arena 24 and $48 \mathrm{~h}$ later for $20 \mathrm{~min}$ each.

Novel object recognition. Mice were placed into a 10 (width) $\times 10$ (depth) $\times 16$ (height $)$ inch contextual arena with clear sidewalls (Coulbourn Instruments) containing two objects (A and B) made of plastic material for a 5 min training session and returned to their home cages. For short-term memory retention, mice were placed back into the same arena $1 \mathrm{~h}$ later with one of the previous objects (i.e., A) and a novel object (C) for a $5 \mathrm{~min}$ testing session. For longer-term memory retention at 24 or $48 \mathrm{~h}$, a different cohort of mice were trained as above except that training lasted $10 \mathrm{~min}$ and testing was performed either 24 or $48 \mathrm{~h}$ later, respectively, during a $10 \mathrm{~min}$ testing session. A different set of objects was used for the 24 and $48 \mathrm{~h}$ memory tests. Exploratory activity of each object was recorded for both training and testing sessions and analyzed by experimenters blinded to genotype and treatment group.

Standard cued and contextual fear conditioning and contextual fear extinction. Mice were placed in a 10 (width) $\times 10$ (depth) $\times 16$ (height) inch square-shaped arena fitted with a metal grid shock floor (Coulbourn Instruments). On the day of training, each mouse was placed in the training context (with striped wallpaper) and allowed to freely explore for $2 \mathrm{~min}$. A $90 \mathrm{~dB}$ tone, the conditioned stimulus (CS), was then presented for $30 \mathrm{~s}$. During the final $2 \mathrm{~s}$ of tone presentation, a $0.7 \mathrm{~mA}$ footshock, the unconditioned stimulus (US), was delivered. CS and US were delivered automatically using tone generator and shocker controlled by TruScan software (Coulbourn Instruments). Mice were then returned to their home cages. Twenty-four hours later, the contextual fear-conditioning test was performed in the training room, where mice were placed in the same context arena without any footshock for 2 min. Two hours after the contextual test, mice were subjected to a cued test. Mice were placed in a novel context (triangular-shaped arena with solid gray plastic walls) in a different room and allowed to freely explore for $2 \mathrm{~min}$. The CS (tone) was then presented for $2 \mathrm{~min}$. Two hours after the cued test, mice were subjected to a control test in which they were placed in another novel context (hexagonal-shaped arena with clear plastic walls) in a third room for 2 min with no presentation of either tone or footshock. Freezing behavior was recorded manually every $5 \mathrm{~s}$ for each of the 2 min assessment periods for the three tests. Freezing behavior was defined as lack of bodily movement with all four paws remaining stationary on the floor except normal respiration. Data were collected and analyzed with experimenters blinded to genotype and treatment group.

One day after cued and contextual fear-conditioning tests, mice were placed in the training context without the footshock for two extinction trials each day, with a $4 \mathrm{~h}$ intertrial interval. Each extinction trial lasted a total of $10 \mathrm{~min}$, and freezing behavior was recorded during the final $2 \mathrm{~min}$ of each trial. One day after the completion of the $8 \mathrm{~d}$ fear extinction trials, 


\section{Round tamoxifen treatment 3 weeks post-tamoxifen}
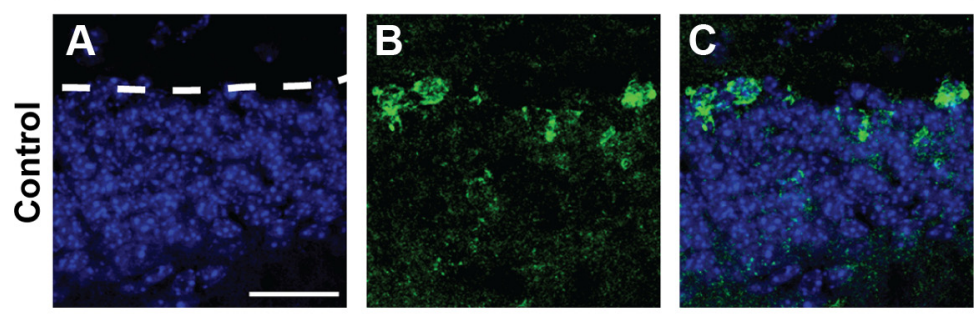

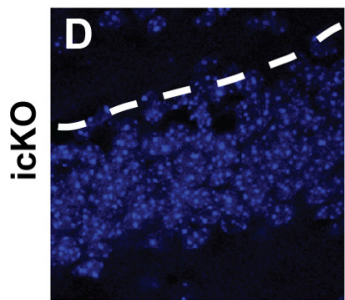

Hoechst

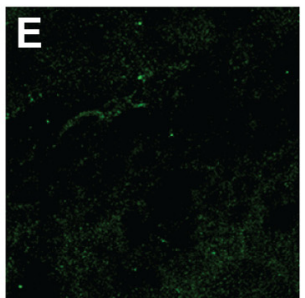

ERK5

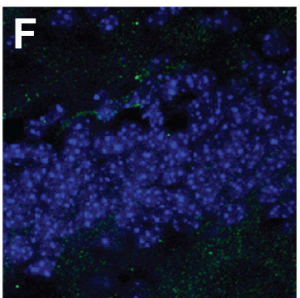

Merge

\section{Rounds tamoxifen treatment 12 weeks post-tamoxifen}

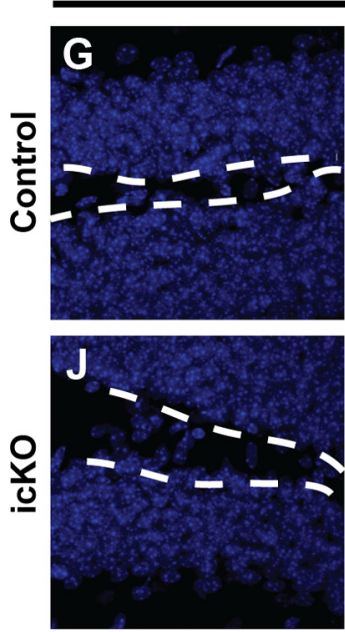

Hoechst
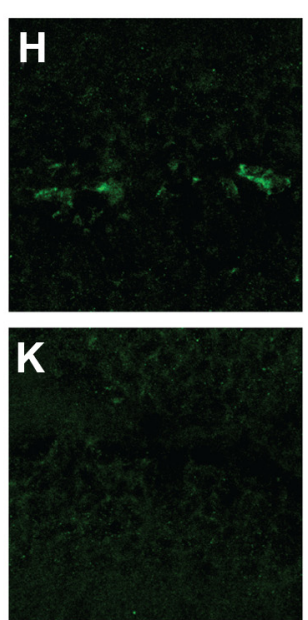

ERK5
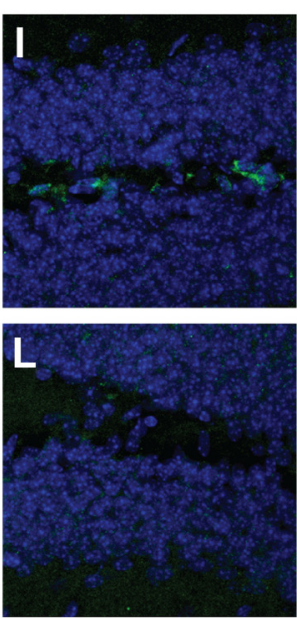

Merge

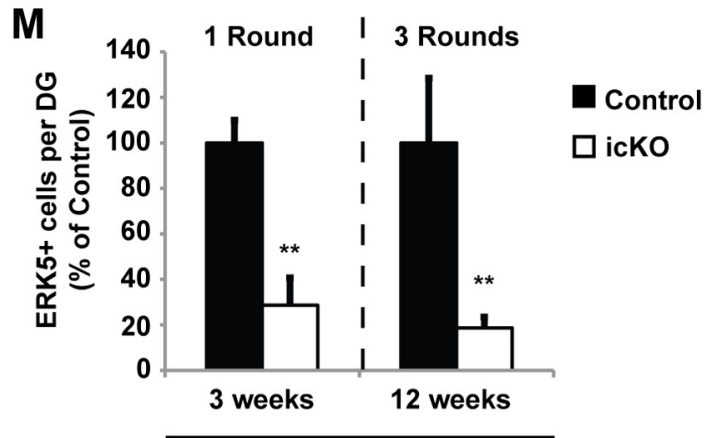

Post-tamoxifen

Figure 3. ERK5-positive cells along the SGZ are significantly reduced 3 and 12 weeks after tamoxifen treatment. $\boldsymbol{A}-\boldsymbol{F}$, ERK5 immunostaining 3 weeks after a $7 \mathrm{~d}$ treatment paradigm with vehicle control $(\boldsymbol{A}-\boldsymbol{C}$, Control) or tamoxifen (D-F, icK0). G- $\boldsymbol{L}$, ERK5 immunostaining 12 weeks after a $3 \times 4 \mathrm{~d}$ treatment paradigm with vehicle control ( $\mathbf{G}-\mathbf{I}$, Control) or tamoxifen (J-L, icK0). Scale bar, $25 \mu \mathrm{m}$. Dashed lines outline the SGZ layer of the dentate gyrus. $\boldsymbol{M}$, Quantification of total ERK5-positive cells per dentate gyrus. Data represent mean percentage from two independent experiments; error bars represent SEM with $n \geq 2$ animals per treatment group per time point per experiment. ${ }^{* *} p<0.01$ mice were placed in a novel context (trapezoidshaped arena with solid gray plastic walls), and freezing behavior was recorded for $2 \mathrm{~min}$.

Modified cued and contextual fear conditioning using weaker electric shock. The same training and testing setup for cued and contextual fear conditioning was used as described above, except that animals were subjected to one to three successive footshocks $(0.3 \mathrm{~mA}, 2 \mathrm{~s}$ each and separated by 2 min intershock intervals).

Morris water maze assay. This was done as described with slight modifications (Wu et al., 1995; M. Zhang et al., 2008). Mice were placed in a circular pool of water at room temperature $\left(25^{\circ} \mathrm{C}\right)(1.2 \mathrm{~m}$ diameter, $25 \mathrm{~cm}$ deep). The water was made opaque using nontoxic white paint. Three extra-maze cues, different in shape and size, were uniformly spaced and placed on the wall surrounding the water tank. A small escape platform $(13 \times 8 \mathrm{~cm})$ made of clear Plexiglas was submerged just below the surface of the water and maintained in a fixed location for the entire training session. To begin a trial or test, mice were randomly started in drop zones, facing the wall, in any of the three quadrants without the platform. A total of 32 trials ( 4 trials per day for 8 consecutive days) were performed during the training session. Mice were allowed to swim for $40 \mathrm{~s}$ to find the platform, or were guided to the platform after $40 \mathrm{~s}$ of the allotted maximum swim time was reached. Each trial ended after mice were allowed to stay on the escape platform for $15 \mathrm{~s}$. A probe test was performed $24 \mathrm{~h}$ after the last training trial in which the escape platform was removed and mice were allowed to swim for $60 \mathrm{~s}$ in search of the escape platform. Reversal training ensued $24 \mathrm{~h}$ after the probe test for a total of 28 trials ( 4 trials per day for 7 consecutive days) where the escape platform was placed in the opposite quadrant from the initial training session. A reversal probe test was performed $24 \mathrm{~h}$ after the last trial of reversal training. Five hours after the reversal probe test, a visible platform test consisting of four trials was performed where a visible platform was placed above the water surface in a new quadrant other than the initial or reversal quadrants and mice were allowed to swim to locate the visible platform. In all sessions and tests, mice were allowed an intertrial interval of $30 \mathrm{~min}$. All data were collected using ANYmaze software (San Diego Instruments) and analyzed off-line with the experimenter blinded to treatment and genotypes.

Pattern separation assay. This was measured by the delayed-nonmatching-to-place test using the eight-arm radial maze (Clelland et al., 2009; Guo et al., 2011). Mice were food restricted $4 \mathrm{~d}$ before beginning the assay until $85-90 \%$ of free-feeding body weight was reached. Each mouse was subjected to four trials per day for 5 consecutive days, with an intertrial interval of $30 \mathrm{~min}$. Each trial was divided into two phases, a training phase and a choice phase. During the training phase, six of eight arms of the radial arm maze were blocked, leaving the sample arm and start arm open, separated by $90^{\circ}$ from each other. Food 
reward was placed at the end of the sample arm. Mice were placed in the maze facing the end of the start arm, allowed to freely explore for 3 min, and were guided to the sample arm unless they retrieved the food reward from the sample arm before the 3 min cutoff time. Mice were allowed to eat for $60 \mathrm{~s}$ in the sample arm before being placed back in their home cage for $\sim 30 \mathrm{~s}$, during which time the maze was rotated $45^{\circ}$ and the arms were cleaned with $5 \%$ acetic acid to minimize odor reference. The choice phase test was conducted immediately after cleaning, during which new sample and start arms were opened and the original arms were blocked, but the relative location of the arms during the training phase remained fixed. Additionally, a test arm was opened and separated by either one arm (separation 2) or three arms (separation 4) from the new sample arm. Each mouse was subjected to the same total number of separation 2 or 4 tests, although the two separations were presented randomly in sequence each day. Food reward was placed at the end of the test arm during the choice phase. Mice were placed in the maze facing the end of the start arm and allowed to make a choice in the maze. When a mouse entered the test arm, it was scored as a correct choice, and the mouse was allowed to eat for $60 \mathrm{~s}$ before being removed from the maze. When a mouse entered the sample arm, reentered the start arm, or did not make a choice within $3 \mathrm{~min}$, it was scored as an incorrect choice. On days 1 and 2, mice that made an incorrect choice were allowed to selfcorrect and explore the maze for a maximum of 3 min before being guided to the test arm and allowed to eat for $60 \mathrm{~s}$. On days 3-5, mice that made an incorrect choice were removed from the maze immediately and not allowed access to food reward. Correct or incorrect choices during the choice phase were scored manually with the experimenter blinded to experimental conditions.

Passive avoidance and remote memory assay. A light/dark chamber (Coulbourn Instruments) with a guillotine trap door separating the two chambers was used. A $60 \mathrm{~W}$ light bulb was placed over the opening of the light chamber, whereas the dark chamber was completely covered with black film. Mice were placed in the light chamber with the trap door closed and were allowed to freely explore for $1 \mathrm{~min}$, after which the trap door was opened and the latency to cross over was recorded. Once mice crossed over into the dark chamber, the trap door was closed, immediately followed by delivery of a mild footshock $(0.7 \mathrm{~mA}, 2 \mathrm{~s})$; mice then remained in the dark chamber for an additional $1 \mathrm{~min}$ before being removed and placed in their home cage. Twenty-four hours later, mice were placed in the light chamber with the trap door closed and were allowed to freely explore for $1 \mathrm{~min}$. After $1 \mathrm{~min}$, the trap door was opened, and latency to cross over to the dark chamber was recorded with a maximum crossover latency cutoff of $5 \mathrm{~min}$. For the remote memory test, mice were tested $21 \mathrm{~d}$ after training using the same procedure as the $24 \mathrm{~h}$ test.

Statistical analysis. All data are expressed as mean \pm SEM from at least two independent experiments $(n \geq 10$ for each treatment group per genotype) for in vivo behavior experiments, or $n \geq 3$ for in vivo cellular quantification data. Student's $t$ test was used to analyze in vivo cellular data. Two-way ANOVA with repeated measures was used to analyze data for all the water maze tests (except the probe test) and fear extinction assays. One-way ANOVA with Fisher's least significant difference post hoc analysis $(\alpha=0.05)$ was used to analyze all other behavior data [n.s., not significant $\left.(p>0.05) ;{ }^{\star} p<0.05 ;{ }^{* *} p<0.01 ;{ }^{* * *} p<0.001\right]$.

\section{Results}

ERK5 expression in the adult mouse brain

ERK5 expression was examined by immunohistochemistry using an affinity-purified ERK5-specific antibody. ERK5 protein was found along the SVZ and the SGZ of the dentate gyrus in the adult mouse brain (Fig. $1 A-D$ ). However, ERK5 was not expressed outside of the adult neurogenic regions, including the cortex and striatum (Fig. $1 E-H$ ). This unique pattern of expression suggested an important function for ERK5 in adult neurogenesis.

\section{Conditional targeting of ERK5 in adult neurogenic regions attenuates adult neurogenesis in the SGZ}

To investigate a role for ERK5 signaling in adult neurogenesis in vivo, we crossed Nestin-CreER ${ }^{\mathrm{TM}}$ mice (Kuo et al., 2006) with erk5 floxed allele mice (X. Wang et al., 2006) to yield Nestin-CreER ${ }^{\mathrm{TM}} / \mathrm{ERK} 5^{\text {loxP/loxP }}$ mice. After tamoxifen treatment, the erk5 gene is conditionally knocked out (ERK5 icKO) specifically in Nestin-expressing neural stem cells in the adult brain of this mouse strain. Thus, erk5 deletion is temporally and spatially regulated and restricted to the adult neurogenic regions, limiting potential side effects on other areas of the brain during embryonic development.

Male Nestin-CreER ${ }^{\mathrm{TM}} / \mathrm{ERK} 5^{\text {loxP/loxP }}$ mice were treated with vehicle (control) or tamoxifen to induce Cre-mediated recombination of erk5 in Nestin-expressing neural stem cells. In a separate set of experiments, tamoxifen administration to Nestin-CreER ${ }^{\mathrm{TM}}$ / 
R26-YFP ${ }^{\text {loxP/loxP }}$ reporter mice confirmed the specificity of tamoxifen-induced, Nestin-CreER ${ }^{\mathrm{TM}}$-mediated recombination (data not shown). Tamoxifen treatment did not affect the general health and overall appearance among littermates. A $7 \mathrm{~d}$ tamoxifen treatment decreased the number of ERK ${ }^{+}$cells in the SGZ by $65 \%$ compared with vehicle controls (Fig. $2 A-D ; t$ test, $p<$ $0.001)$. This was accompanied by a significant reduction in the total number of NeuroD ${ }^{+}$cells (Fig. $2 E-G$; $t$ test, $p=0.028$ ) and adult-born, mature neurons (NeuN and BrdU double-positive cells among total $\mathrm{BrdU}^{+}$population) along the SGZ (Fig. $2 \mathrm{H}-J$; $t$ test, $p=0.023$ ). NeuroD is a marker for transiently amplifying progenitors and/or newborn neurons, whereas $\mathrm{NeuN}$ is a marker for mature neurons. These data suggest a critical role for ERK5 in promoting adult neurogenesis in the SGZ in vivo.

\section{ERK5 icKO mice had no memory for novel objects measured} $48 \mathrm{~h}$ after training

To examine the effect of conditional erk5 deletion on hippocampus-dependent animal behavior, we used a modified tamoxifen dosing regimen (Imayoshi et al., 2008) to ensure prolonged erk5 gene deletion and a cumulative loss of ERK $5^{+}$cells over a period of time in the neurogenic regions. Tamoxifen was administered once per day for $4 \mathrm{~d}$ in each cycle, for a total of three cycles with a 2 week intercycle interval (Fig. 3 ). The number of ERK5 ${ }^{+}$ cells along the SGZ was reduced $80 \%$ even 3 months after the last dose of tamoxifen treatment (Fig. $3 M$; $t$ test, $p=0.005$ for 3 week and $p=0.007$ for 3 month analysis), which provided a relatively large time window (at least 3 months) for behavior tests.

We first assessed motor function of ERK5 icKO and control mice and found no statistically significant differences in theiropen field activities or their ability to habituate to the open field in 3 consecutive days (Fig. $4 \mathrm{~B}$, one-way ANOVA, $F_{(1,2)}=22.16$, $p=0.13$; Fig. $4 C, F_{(1,2)}=1.32, p=0.46$; Fig. $4 D, F_{(1,2)}=29.51$, $p=0.12$; Fig. $\left.4 E, F_{(1,2)}=29.51, p=0.12\right)$. Furthermore, ERK5 icKO mice exhibited no defects in memory for novel objects measured $1 \mathrm{~h}$ after training (Fig. $5 A, B$; one-way ANOVA, $F_{(1,27)}=$ 58.6, $p<0.001$ for control mice and $F_{(1,19)}=42.11, p<0.001$ for ERK5 icKO mice in Fig. $5 B$ ) or $24 \mathrm{~h}$ after training (Fig. $5 C, D$; one-way ANOVA, $F_{(1,13)}=11.5, p=0.005$ for control and $F_{(1,19)}=9.08, p=0.007$ for ERK5 icKO in $\left.D\right)$. The lack of any deficits in memory for novel objects measured 1 and $24 \mathrm{~h}$ after training, in the open-field test and open-field habituation, suggests that ERK5 icKO mice have no defects in vision and general mobility and are not ataxic.

Interestingly, ERK5 icKO mice had no memory for novel objects measured $48 \mathrm{~h}$ after training (Fig. 5E, F; one-way ANOVA, $F_{(1,13)}=30.36, p<0.001$ for control and $F_{(1,19)}=0.0062, p=$ 0.94 for ERK5 icKO in Fig. $5 F$ ), suggesting that ERK5 icKO mice may be deficient in longer-term memory.

Inducible and conditional deletion of the erk5 gene interferes with a challenging form of contextual fear memory and contextual fear extinction

Animals were subjected to contextual fear conditioning (Fig. $6 A$ ), a form of hippocampus-dependent learning and memory. In initial experiments, mice were trained with a single 0.7 $\mathrm{mA}, 2 \mathrm{~s}$ footshock, which is a standard method used in contextual fear conditioning (Shan et al., 2008). Using this training protocol, ERK5 icKO mice did not exhibit defects in memory for contextual fear measured $24 \mathrm{~h}$ after training (Fig. $6 B$; one-way ANOVA, $\left.F_{(1,17)}=1.30, p=0.27\right)$. The contextual memory for both ERK5 icKO and control mice was context
1 hour Test
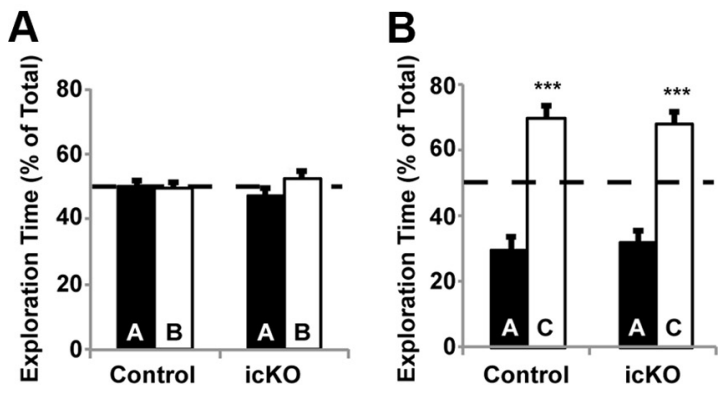

24 hour Test
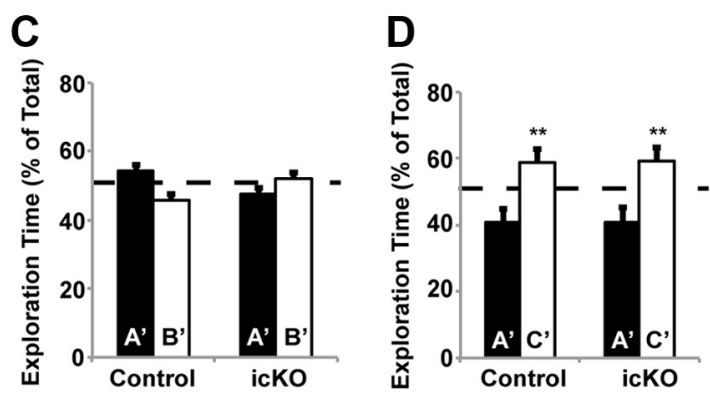

\section{8 hour Test}
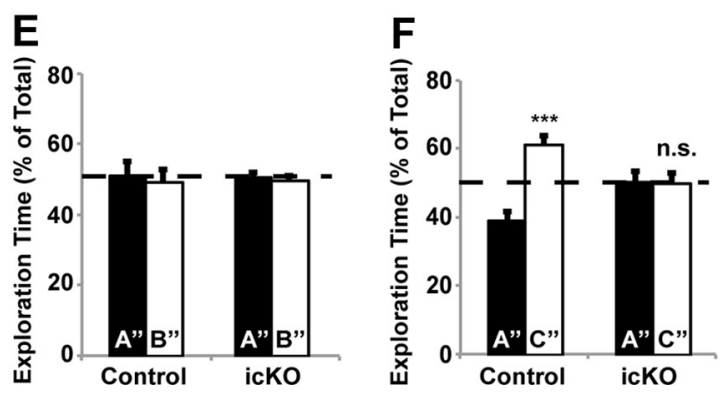

Figure 5. ERK5 icKO mice are deficient in the memory for novel object tested at $48 \mathrm{~h}$ after training. $A, B$, Memory for novel object $1 \mathrm{~h}$ after training is not affected in ERK5 icKO mice. $A$, During the training session, control and ERK5 icKO mice were presented with two objects, A and $B$, for $5 \mathrm{~min}$, and the percentage of time spent exploring each object was quantified. $B$, During the test session, conducted $1 \mathrm{~h}$ later, control and ERK 5 icKO mice were presented again with two objects, A (familiar) and C (novel), for $5 \mathrm{~min}$, and the percentage of time spent exploring each object was quantified. C, D, Memory for the novel object $24 \mathrm{~h}$ after training is not affected in ERK5 $\mathrm{icK}$ O mice. $C$, A new cohort of mice was used. The training session was conducted for 10 min with objects $A^{\prime}$ and $B^{\prime}$, and exploration time was quantified. $\boldsymbol{D}$, The test session was conducted $24 \mathrm{~h}$ later with objects $\mathrm{A}^{\prime}$ and $\mathrm{C}^{\prime}$ for $10 \mathrm{~min}$. $\boldsymbol{E}, \boldsymbol{F}$, ERK5 icK0 mice have no memory for the novel object $48 \mathrm{~h}$ after training. $\boldsymbol{E}$, After the $24 \mathrm{~h}$ test, animals were trained with objects $A^{\prime \prime}$ and $B^{\prime \prime}$ for 10 min. $F$, The test session with presentations of objects $A^{\prime \prime}$ and $C^{\prime \prime}$ was performed $48 \mathrm{~h}$ later. Data represent mean exploration time from three independent experiments with $n \geq 8$ animals per treatment group per experiment. n.s., Not significant. ${ }^{* *} p<0.01 ;{ }^{* * *} p<0.001$.

specific since the mice did not show training-induced decreases in mobility when tested in a novel context $24 \mathrm{~h}$ after training (Fig. $6 C$; one-way ANOVA, $F_{(1,17)}=1.31, p=0.27$ ). These data are consistent with other data using the $0.7 \mathrm{~mA}$ footshock paradigm reporting that adult neurogenesis is not required for contextual fear conditioning (Dupret et al., 2008; C. L. Zhang et al., 2008; Deng et al., 2009). Furthermore, memory for auditory-cued fear conditioning, a form of amygdaladependent but hippocampus-independent learning and memory, was also unaffected in ERK5 icKO mice (Fig. $6 D$; one-way ANOVA, $\left.F_{(1,17)}=0.15, p=0.71\right)$. 
Although targeted deletion of ERK5 did not affect the formation of contextual fear memory, ERK5 icKO mice were impaired in contextual fear extinction (Fig. $6 E$; two-way ANOVA, $F_{(1,8)}=17.68, p=$ $0.003)$. This is consistent with another report implicating adult neurogenesis in contextual fear extinction (Deng et al., 2009). The contextual memory that persisted after fear extinction trials was context dependent since neither ERK5 icKO nor control mice showed increased freezing when exposed to a novel context after the $8 \mathrm{~d}$ fear extinction training (Fig. $6 F$; one-way ANOVA, $F_{(1,17)}=3.27, p=$ 0.09).

Contextual fear memory generated with a single $0.7 \mathrm{~mA}$ footshock is a very strong (thus relatively easy) form of episodic memory that persists up to 11 weeks (Shan et al., 2008). Contextual fear extinction is a distinct form of hippocampusdependent learning and memory (Fischer et al., 2007). It may be more challenging than contextual fear conditioning because it is an active form of forgetting in which the animals learn to dissociate the context from the footshock. For example, although it took only a single $0.7 \mathrm{~mA}$ footshock to establish the initial contextual fear memory, it took repeated trials of context exposure over the course of $8 \mathrm{~d}$ without the footshock for this memory to undergo extinction in control mice. This prompted us to investigate whether targeted deletion of ERK5 interferes with contextual fear memory when mice are subjected to a more challenging form of contextual memory training. We examined the sensitivity of wild-type C57/BL6 mice to contextual fear conditioning using a weaker aversive stimulus, $0.3 \mathrm{~mA}$ footshock. When C57/BL6 mice were trained for contextual fear memory using a $2 \mathrm{~s}, 0.3 \mathrm{~mA}$ footshock, they had to be shocked three times to generate contextual memory as strong as that generated with a single $2 \mathrm{~s}, 0.7 \mathrm{~mA}$ footshock (Fig. $7 A, B$ ). Thus, contextual fear training using the $0.3 \mathrm{~mA}$ footshock is a weaker training paradigm and more difficult compared with the single $0.7 \mathrm{~mA}$ footshock.

Interestingly, when ERK5 icKO mice were trained for contextual fear memory using this more challenging protocol (three times, $0.3 \mathrm{~mA}$ footshocks, $2 \mathrm{~s}$ each), they responded to the shocks as well as control mice during the three-shock training session (data not shown). However, memory for contextual fear, measured $24 \mathrm{~h}$ after training, was significantly reduced in ERK5 icKO mice (Fig. $7 C$; one-way ANOVA, $F_{(1,18)}=7.13, p=0.01$ ). The remaining fear memory was still context specific because animals did not freeze in a novel context (Fig. 7D; one-way ANOVA, $\left.F_{(1,12)}=0.72, p=0.41\right)$ and erk5 deletion did not affect cued-fear conditioning (Fig. $7 E$; one-way ANOVA, $F_{(1,12)}=2.00, p=0.18$ ). The fact that the freezing response immediately after each shock and cued memory were normal in ERK5 icKO mice suggests that the mutant mice exhibit shock sensitivity comparable to control mice. Collectively, these data indicate that targeted deletion of erk5 attenuates contextual fear extinction and the formation of contextual memory generated by a more demanding training protocol using a weaker shock paradigm than normally used in contextual fear conditioning.

\section{Effects of conditional erk5 deletion on spatial learning and memory}

Animals were subjected to the Morris water maze test (Fig. 8), a spatial learning and memory task that is also hippocampus dependent. Although ERK5 icKO mice initially took a little longer to locate the hidden platform on day 1 , they learned to locate the hidden platform almost as well as control mice overall over the course of an $8 \mathrm{~d}$ training period (Fig. $8 \mathrm{~B}$; two-way ANOVA, $F_{(1,7)}=3.10, p=0.12$ ). There was also no significant difference when ERK5 icKO and control mice were subjected to a probe trial $24 \mathrm{~h}$ after training (Fig. $8 \mathrm{C}$; one-way ANOVA, $\left.F_{(7,146)}=58.71, p=0.12\right)$.

We then subjected animals to reversal training in which the hidden platform was moved to the opposite location. Reversal training may be more demanding than the initial hidden platform training because the mice need to actively forget the old location of the hidden platform and learn to find it in a new location. Interestingly, ERK5 icKO mice swam longer distances than control mice to find the new platform during a $7 \mathrm{~d}$ period of reversal training (Fig. $8 D$; two-way ANOVA, $F_{(1,6)}=5.56, p=$ $0.05)$. Furthermore, whereas control mice spent much more time in the new target quadrant than in the old one during the subsequent probe test, ERK5 icKO mice spent the same amount of time 


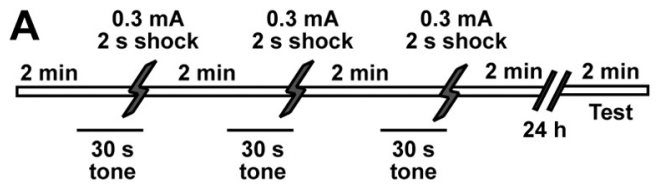

Wild Type C57/BL6
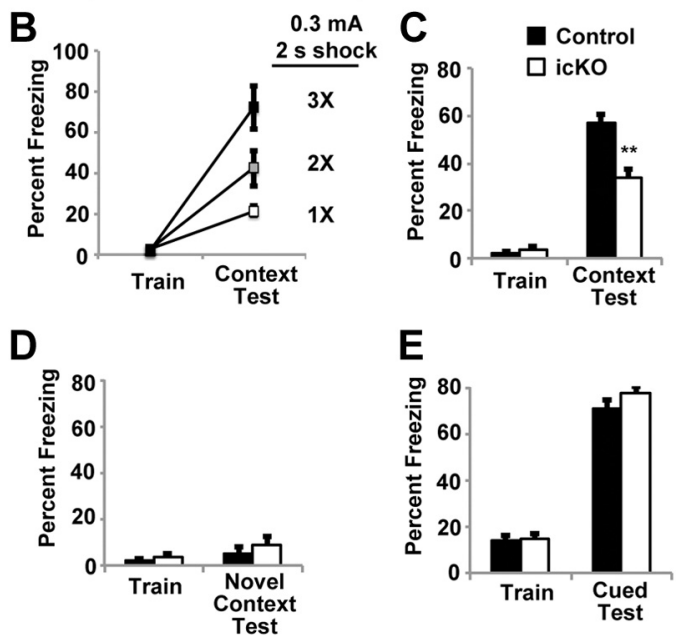

Figure 7. ERK5 icK0 mice exhibit reduced contextual fear memory when animals were trained with weaker electric footshocks. $A$, Schematic illustration of the modified cuedcontextual fear-conditioning paradigm using $0.3 \mathrm{~mA}$ shock intensity delivered up to three times. $\boldsymbol{B}, \mathrm{C} 57 \mathrm{BL} / 6$ mice were subjected to one, two, or three footshocks $(0.3 \mathrm{~mA}, 2$ s each), with 2 min intershock intervals to generate a dose-dependent fear-conditioning response. Freezing behavior in the same context but without footshock was recorded $24 \mathrm{~h}$ later. For subsequent experiments in $\boldsymbol{C}-\boldsymbol{E}$, animals were subjected to three footshocks ( $0.3 \mathrm{~mA}, 2$ s each), with $2 \mathrm{~min}$ intershock intervals. $\boldsymbol{C}$, When placed into the same shocking context $24 \mathrm{~h}$ later, contextual fear memory was reduced in ERK5 icK0 mice. $\boldsymbol{D}$, The fear memory was context specific because animals did not freeze when placed into a novel context $24 \mathrm{~h}$ after training. $\boldsymbol{E}$, Memory for the hippocampus-independent, auditory-cued fear conditioning measured $24 \mathrm{~h}$ after training was unaffected in ERK5 icK0 mice. Data are mean \pm SEM from two independent experiments with $n \geq 6$ per treatment group per experiment. ${ }^{* *} p<0.01$.

searching in both quadrants (Fig. $8 E, G$; one-way ANOVA, $F_{(7,145)}=14.31, p=0.002$ for Fig. $8 E$ between control and ERK5 icKO mice; $F_{(7,145)}=14.31, p<0.001$ for control mice between old and new quadrants; $F_{(7,145)}=14.31, p=0.143$ for ERK5 icKO mice between old and new quadrants). Consistently, ERK5 icKO mice spent less time in the target platform zone than control mice during the reversal probe test (Fig. $8 F$; one-way ANOVA, $F_{(1,31)}=0.85, p=0.36$ for the probe test and $F_{(1,31)}=8.26, p=$ 0.007 for the reversal probe test). These data suggest that ERK5 icKO mice exhibit impaired acquisition of newer spatial information and did not learn the new location of the hidden platform as well as control mice. However, ERK5 icKO mice swam similar total distances with similar speed as control mice measured during the first probe test and the reversal probe test (data not shown). Furthermore, ERK5 icKO mice performed equally well as the control mice in the visible platform test, performed $1 \mathrm{~d}$ after the reversal probe test (data not shown). Thus, the deficiency of ERK5 icKO mice in acquisition of newer spatial information in the reversal hidden platform test was not attributable to a procedural learning deficit, their lack of ability to swim, or motivation to escape from the water.

ERK5 icKO mice are deficient in pattern separation

ERK5 icKO mice were subjected to the radial arm maze pattern separation assay, a form of spatial learning and memory that is dentate gyrus dependent (Farioli-Vecchioli et al., 2008; Clelland et al., 2009; Guo et al., 2011) (Fig. 9A). Pattern separation is the process of transforming similar representations or memories into highly dissimilar, nonoverlapping representations. Thus, it is also considered a difficult form of hippocampal memory formation (Clelland et al., 2009; Guo et al., 2011). ERK5 icKO mice displayed a deficit in this form of pattern separation at both separations 2 and 4 (Fig. 9B; one-way ANOVA, $\left.F_{(3,63)}=3.94, p=0.012\right)$.

\section{Remote fear memory is impaired in ERK5 icKO mice}

Passive avoidance is another form of hippocampus-dependent fear conditioning. We analyzed ERK5 icKO mice for their ability to learn this task and to retain remote fear memories (Fig. 10). A mild footshock $(0.7 \mathrm{~mA}, 2 \mathrm{~s})$ was delivered once mice crossed over into the dark chamber during training. ERK5 icKO mice showed similar crossover latency as control mice when tested $24 \mathrm{~h}$ after training, suggesting that they learned the task and can retrieve the memory. Interestingly, ERK5 icKO mice showed no remote memory measured $21 \mathrm{~d}$ after training (one-way ANOVA, $\left.F_{(5,40)}=40.34, p<0.001\right)$. These data define a new role for adult neurogenesis in the expression of remote memory.

\section{Discussion}

New neurons are constantly born in the dentate gyrus of the hippocampus in the adult mammalian brain. However, the functional impact of these adult-born neurons on hippocampusdependent functions is still an open question. Furthermore, signaling mechanisms regulating adult neurogenesis are incompletely defined. Our goal was to investigate the role of ERK5 MAP kinase in the regulation of adult hippocampal neurogenesis and associated physiological functions.

Here we report that the expression of ERK5 MAP kinase is restricted to the two neurogenic regions in the adult mouse brain. This pattern of expression distinguishes ERK5 from other signaling molecules implicated in adult neurogenesis, including NeuroD, sonic hedgehog, and Wnt, which are more widely expressed in the brain (Kenney et al., 2004; Lie et al., 2005; Gao et al., 2009; Suh et al., 2009). It also suggests that ERK5 may regulate adult neurogenesis. Indeed, conditional deletion of the erk5 gene, specifically in the neurogenic regions, attenuated adult hippocampal neurogenesis in vivo.

Although several studies have attempted to assess the role of adult neurogenesis in hippocampus-dependent memory formation, the results have been inconsistent (Deng et al., 2010; Leuner and Gould, 2010). For example, although some studies showed that ablation of adult neurogenesis interferes with contextual fear response (Imayoshi et al., 2008), contextual fear memory (Saxe et al., 2006), contextual trace memory (Guo et al., 2011), contextual fear extinction (Deng et al., 2009), and contextual fear memory transfer out of the hippocampus (Kitamura et al., 2009), other studies suggest that inhibition of adult neurogenesis does not affect contextual fear conditioning (Shors et al., 2002; Dupret et al., 2008; C. L. Zhang et al., 2008; Deng et al., 2009; Jaholkowski et al., 2009). Several factors may contribute to these seemingly contradictory results, including design of the behavior studies. Here, we sought to examine the effects of targeted erk5 deletion on contextual fear memory by directly comparing two paradigms that have been used in previous reports, one time $0.7 \mathrm{~mA}, 2 \mathrm{~s}$ versus three times $0.3 \mathrm{~mA}, 2 \mathrm{~s}$ each (Imayoshi et al., 2008; Deng et al., 2009). Interestingly, ERK5 icKO mice show reduced contextual fear memory using the three times $0.3 \mathrm{~mA}, 2 \mathrm{~s}$ footshock but not the one time $0.7 \mathrm{~mA}, 2 \mathrm{~s}$ footshock. 
Adult neurogenesis has also been implicated in spatial learning and memory in some studies (Dupret et al., 2008; FarioliVecchioli et al., 2008; Imayoshi et al., 2008; C. L. Zhang et al., 2008; Clelland et al., 2009; Garthe et al., 2009; Jessberger et al., 2009; Creer et al., 2010; Guo et al., 2011), but not in others (Shors et al., 2002; Meshi et al., 2006; Saxe et al., 2006; DenisDonini et al., 2008; Jaholkowski et al., 2009). In addition to the differences in experimental design of behavior assays, several other factors may contribute to these contradictory results, including the specificity of the methods used to ablate adult neurogenesis. Many early studies used $\mathrm{X}$-irradiation or antimitotic drugs to ablate adult neurogenesis. Although these methods are effective at reducing adult neurogenesis, they are not specific to adult neural progenitor cells (aNPCs) and can affect other neurons. These treatments may also lead to significant side effects, including neural inflammation. More recent studies used transgenic expression of a lethal gene, such as diphtheria toxin using the Nestin-CreER ${ }^{\mathrm{T} 2}$; NSE-DTA mice (Imayoshi et al., 2008), thymidine kinase (Saxe et al., 2006; Deng et al., 2009), or the pro-apoptotic protein Bax (Dupret et al., 2008) to kill adult-born cells. Although these approaches are more specific to aNPCs than irradiation or antimitotic drugs, greatly increased cell death in the dentate gyrus may interfere with normal hippocampal function. In other studies, a specific gene, such as cyclin D2, Wnt, TLX, or PI3K, was deleted or inhibited (DenisDonini et al., 2008; C. L. Zhang et al., 2008; Jaholkowski et al., 2009; Jessberger et al., 2009). However, these genes are also expressed in neurons of the brain, and the deletion or inhibition of these genes in mice may not be restricted to aNPCs. The off-target effects associated with these approaches may contribute to ambiguity in interpretation of the results.

The contradictory results in the literature regarding the functional impact of adult-born neurons on hippocampusdependent function necessitated studies using more specific genetic approaches with less off-target side effects to manipulate adult neurogenesis. One strategy uses transgenic mouse technology to conditionally disrupt a specific gene both temporally and spatially in adult neurogenic regions. Indeed, a recent study used this approach to delete fragile $\mathrm{X}$ mental retardation protein (FMRP), a protein that is enriched in neurons but also expressed in adult neural stem cells. This study reported evidence that adult neurogenesis contributes to learning and memory (Guo et al., 2011). A superior strategy to disrupt adult neurogenesis would be to identify a signaling molecule that is only ex-

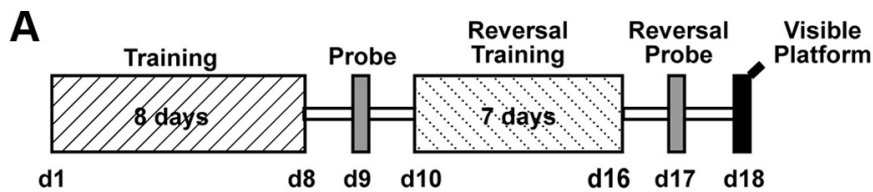

B

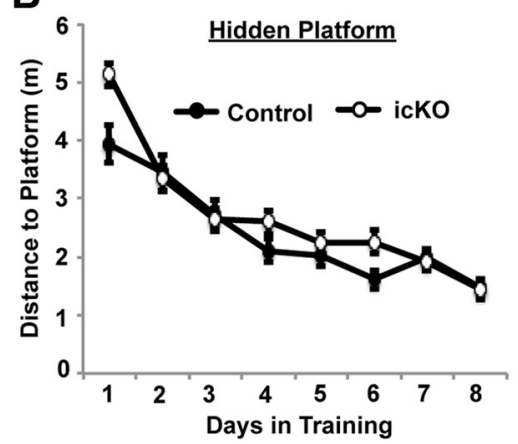

C

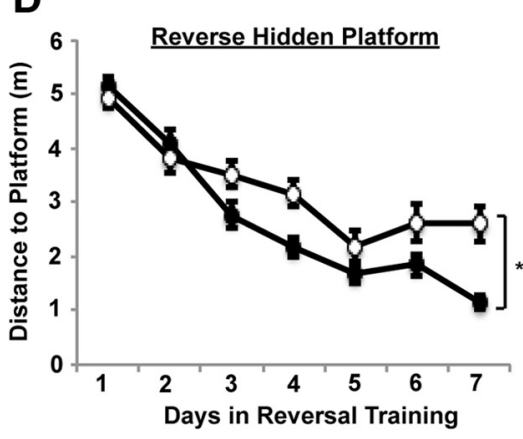

E

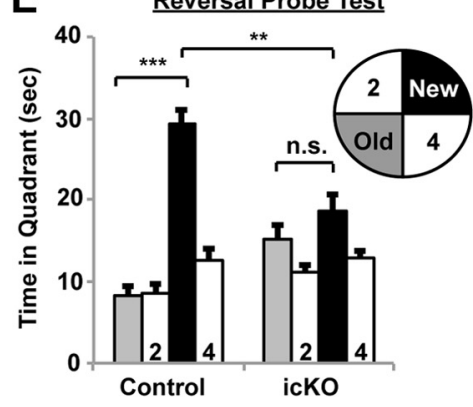

G

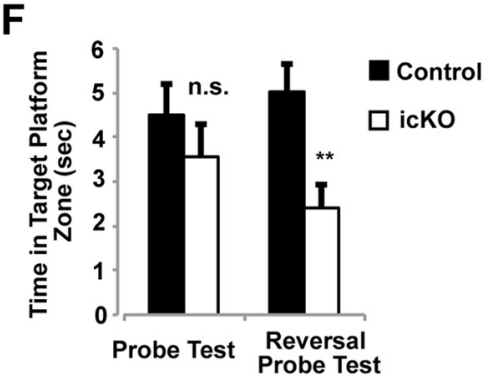

Figure 8. ERK5 icK0 mice show impaired learning of newer spatial information. $\boldsymbol{A}$, Schematic depiction of the experimental design. Mice were subjected to $8 \mathrm{~d}$ of training [ 4 sessions per day, 30 min intersession interval, from day 1 (d1) to d8] in the hidden platform water maze. A probe test was conducted $24 \mathrm{~h}$ later. Mice were then subjected to $7 \mathrm{~d}$ of reversal training ( 4 sessions per day, 30 min intersession interval) where the escape hidden platform was relocated to the opposite quadrant of the water maze. This was followed by the reversal probe test and visible platform test. $\boldsymbol{B}$, Target (in quadrant 1 ) acquisition in the hidden platform, quantified as swim distance to platform, was similar in control and ERK5 icKO mice, demonstrating similar spatial learning. C, ERK5 icKO mice spent a similar amount of time in the virtual target quadrant as control mice in the probe test, suggesting that ERK5 icK0 mice retained the spatial memory. $\boldsymbol{D}$, Swim distance to escape in the reversal hidden platform training where the hidden platform was moved to quadrant 3. ERK5 icK0 mice swam longer distances, suggesting impaired learning of newer spatial information. $\boldsymbol{E}$, Control but not ERK5 icKO mice spent significantly more time in the new virtual target quadrant 3 than in the previous virtual target quadrant 1 during the reversal probe test. $\boldsymbol{F}$, ERK5 icK0 mice spent less time in the target platform zone than control mice during the reversal probe test. $\mathbf{G}$, Representative computer-generated tracing of the swim-and-search pattern of control versus ERK5 icK0 mice in the initial probe test and the reversal probe test. Data are mean \pm SEM from two independent experiments with $n \geq 10$ per treatment group per experiment. n.s., Not significant. ${ }^{*} p<0.05 ;{ }^{* *} p<0.01$; ${ }^{* * *} p<0.001$.

pressed in neurogenic regions of the brain that is required for adult neurogenesis and to conditionally disrupt that gene in adult neurogenic regions. The present study identifies ERK5 MAP kinase as such a molecule. We have demonstrated spatially and temporally controlled deletion of erk5 in the neurogenic regions of the adult brain, which led to significant inhibition of adult neurogenesis in the dentate gyrus. 


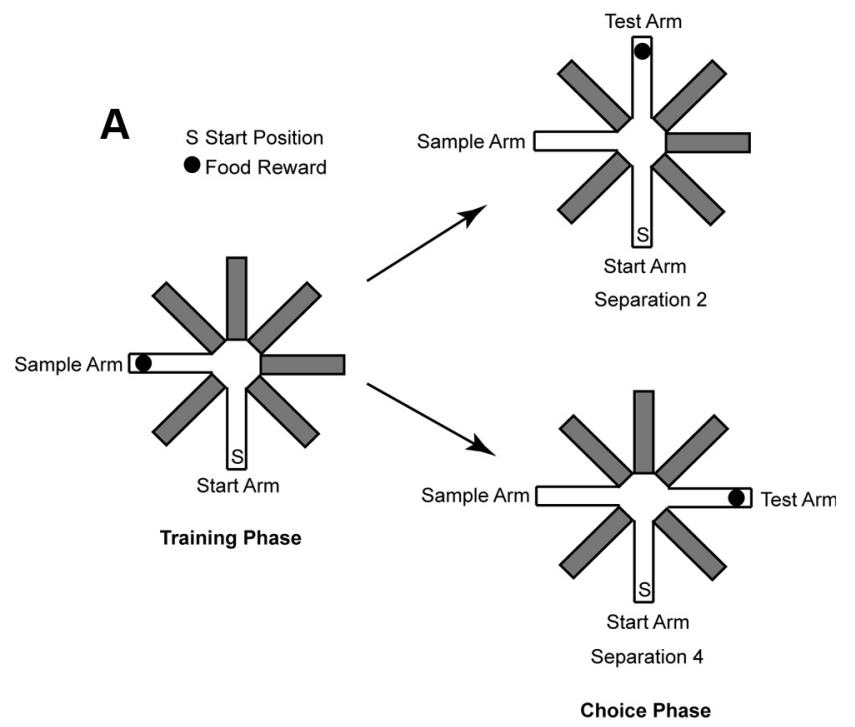

B

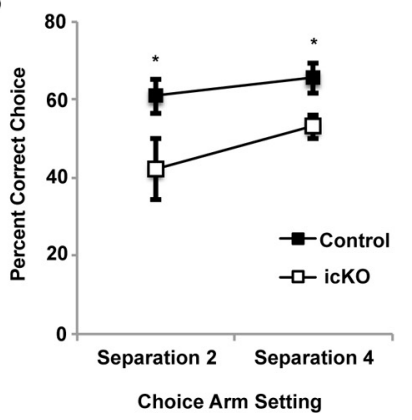

Figure 9. ERK5 icKO mice are deficient in pattern separation. $\boldsymbol{A}$, Schematic illustration of the experimental design. $\boldsymbol{B}$, ERK5 icK0 mice made fewer correct choices in both the easier (separation 4) and more difficult (separation 2) pattern separations. Data are from the last day of a 5 d experimental paradigm and represent mean \pm SEM with $n \geq 10$ per treatment group. ${ }^{*} p<0.05$.

Our data showed that ERK5 icKO mice do not exhibit general behavioral defects in the open-field activity assay or open-field habituation, memory for novel object at 1 and $24 \mathrm{~h}$, cued-fear conditioning, contextual fear conditioning using a $0.7 \mathrm{~mA}$ footshock, or the acquisition of the initial spatial learning and memory in Morris water maze training. Thus, these mice have no defects in vision, general mobility, general curiosity, ability to swim, motivation to escape from the water, or procedural learning, and they are not ataxic.

However, it is interesting that targeted deletion of erk5 interfered with novel object memory measured $48 \mathrm{~h}$ after training, contextual fear extinction, contextual fear memory from weaker footshocks $(0.3 \mathrm{~mA})$, reversal water maze test, and pattern separation. These data suggest that ERK5 knockout mice are deficient in several forms of hippocampusdependent memory, which share the property of being more challenging. Several studies have implicated the dentate gyrus in pattern separation (Clelland et al., 2009; Creer et al., 2010; Guo et al., 2011). Data presented in this study provide additional genetic evidence supporting a role for adult neurogenesis in this dentate gyrus-dependent function. The fact that erk5 deletion interferes with fear extinction and reversal of hidden platform training suggests that adult neurogenesis may be important for learning that requires active forgetting of a prior memory.
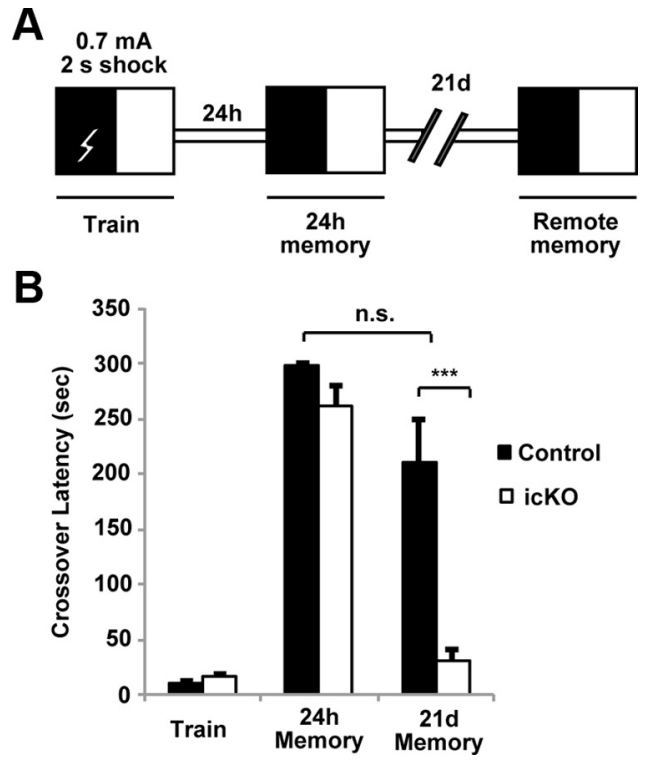

Figure 10. Remote memory in the passive avoidance assay is impaired in ERK5 icK0 mice. Mice were trained with one $0.7 \mathrm{~mA}, 2$ s footshock in the passive avoidance assay. $A$, Schematic illustration of the experimental design. $\boldsymbol{B}$, Crossover latency was measured $24 \mathrm{~h}$ or $21 \mathrm{~d}$ after training. Data represent mean \pm SEM with $n \geq 10$ per treatment group. n.s., Not significant. ${ }^{* * *} p<0.001$.

How enduring long-term, or remote memory is formed is an important question. Although recent studies have shed light on mechanisms responsible for the formation of recent hippocampus-dependent memories, much less is known regarding how recent memories are transformed into remote memories (Frankland and Bontempi, 2005). We discovered that although ERK5 icKO mice have normal fear memory $1 \mathrm{~d}$ after training in the passive avoidance assay, their remote memory at $21 \mathrm{~d}$ was completely disrupted. These data are the first demonstration that adult neurogenesis contributes to the expression of remote memory.

Together, our data identify ERK5 MAP kinase as a novel signaling pathway regulating adult neurogenesis in the dentate gyrus and demonstrate a causal relationship between ERK5regulated adult neurogenesis and the expression of remote memory as well as several challenging forms of hippocampusdependent memory formation, including fear extinction. This study also provides the first evidence for a physiological function of ERK5 in vivo in the adult mammalian brain.

\section{References}

Altman J, Das GD (1965) Autoradiographic and histological evidence of postnatal hippocampal neurogenesis in rats. J Comp Neurol 124:319-335.

Alvarez-Buylla A, Theelen M, Nottebohm F (1988) Birth of projection neurons in the higher vocal center of the canary forebrain before, during, and after song learning. Proc Natl Acad Sci U S A 85:8722-8726.

Athos J, Impey S, Pineda VV, Chen X, Storm DR (2002) Hippocampal CREmediated gene expression is required for contextual memory formation. Nat Neurosci 5:1119-1120.

Atkins CM, Selcher JC, Petraitis JJ, Trzaskos JM, Sweatt JD (1998) The MAPK cascade is required for mammalian associative learning. Nat Neurosci 1:602-609.

Cavanaugh JE, Ham J, Hetman M, Poser S, Yan C, Xia Z (2001) Differential regulation of mitogen-activated protein kinases ERK1/2 and ERK5 by neurotrophins, neuronal activity, and cAMP in neurons. J Neurosci 21:434-443.

Clelland CD, Choi M, Romberg C, Clemenson GD Jr, Fragniere A, Tyers P, Jessberger S, Saksida LM, Barker RA, Gage FH, Bussey TJ (2009) A func- 
tional role for adult hippocampal neurogenesis in spatial pattern separation. Science 325:210-213.

Creer DJ, Romberg C, Saksida LM, van Praag H, Bussey TJ (2010) Running enhances spatial pattern separation in mice. Proc Natl Acad Sci U S A 107:2367-2372.

Cundiff P, Liu L, Wang Y, Zou J, Pan YW, Abel G, Duan X, Ming GL, Englund C, Hevner R, Xia Z (2009) ERK5 MAP kinase regulates Neurogenin1 during cortical neurogenesis. PLoS One 4:e5204.

Deng W, Saxe MD, Gallina IS, Gage FH (2009) Adult-born hippocampal dentate granule cells undergoing maturation modulate learning and memory in the brain. J Neurosci 29:13532-13542.

Deng W, Aimone JB, Gage FH (2010) New neurons and new memories: how does adult hippocampal neurogenesis affect learning and memory? Nat Rev Neurosci 11:339-350.

Denis-Donini S, Dellarole A, Crociara P, Francese MT, Bortolotto V, Quadrato G, Canonico PL, Orsetti M, Ghi P, Memo M, Bonini SA, FerrariToninelli G, Grilli M (2008) Impaired adult neurogenesis associated with short-term memory defects in NF-kappaB p50-deficient mice. J Neurosci 28:3911-3919.

Di Benedetto B, Hitz C, Hölter SM, Kühn R, Vogt Weisenhorn DM, Wurst W (2007) Differential mRNA distribution of components of the ERK/ MAPK signalling cascade in the adult mouse brain. J Comp Neurol 500:542-556.

Döbrössy MD, Drapeau E, Aurousseau C, Le Moal M, Piazza PV, Abrous DN (2003) Differential effects of learning on neurogenesis: learning increases or decreases the number of newly born cells depending on their birth date. Mol Psychiatry 8:974-982.

Dupret D, Fabre A, Döbrössy MD, Panatier A, Rodríguez JJ, Lamarque S, Lemaire V, Oliet SH, Piazza PV, Abrous DN (2007) Spatial learning depends on both the addition and removal of new hippocampal neurons. PLoS Biol 5:e214.

Dupret D, Revest JM, Koehl M, Ichas F, De Giorgi F, Costet P, Abrous DN, Piazza PV (2008) Spatial relational memory requires hippocampal adult neurogenesis. PLoS One 3:e1959.

Farioli-Vecchioli S, Saraulli D, Costanzi M, Pacioni S, Cinà I, Aceti M, Micheli L, Bacci A, Cestari V, Tirone F (2008) The timing of differentiation of adult hippocampal neurons is crucial for spatial memory. PLoS Biol 6:e246.

Finegan KG, Wang X, Lee EJ, Robinson AC, Tournier C (2009) Regulation of neuronal survival by the extracellular signal-regulated protein kinase 5 . Cell Death Differ 16:674-683.

Fischer A, Radulovic M, Schrick C, Sananbenesi F, Godovac-Zimmermann J, Radulovic J (2007) Hippocampal Mek/Erk signaling mediates extinction of contextual freezing behavior. Neurobiol Learn Mem 87:149-158.

Frankland PW, Bontempi B (2005) The organization of recent and remote memories. Nat Rev Neurosci 6:119-130.

Gao Z, Ure K, Ables JL, Lagace DC, Nave KA, Goebbels S, Eisch AJ, Hsieh J (2009) Neurod1 is essential for the survival and maturation of adultborn neurons. Nat Neurosci 12:1090-1092.

Garthe A, Behr J, Kempermann G (2009) Adult-generated hippocampal neurons allow the flexible use of spatially precise learning strategies. PLoS One 4:e5464.

Guo W, Allan AM, Zong R, Zhang L, Johnson EB, Schaller EG, Murthy AC, Goggin SL, Eisch AJ, Oostra BA, Nelson DL, Jin P, Zhao X (2011) Ablation of Fmrp in adult neural stem cells disrupts hippocampus-dependent learning. Nat Med 17:559-565.

Imayoshi I, Sakamoto M, Ohtsuka T, Takao K, Miyakawa T, Yamaguchi M, Mori K, Ikeda T, Itohara S, Kageyama R (2008) Roles of continuous neurogenesis in the structural and functional integrity of the adult forebrain. Nat Neurosci 11:1153-1161.

Jaholkowski P, Kiryk A, Jedynak P, Ben Abdallah NM, Knapska E, Kowalczyk A, Piechal A, Blecharz-Klin K, Figiel I, Lioudyno V, Widy-Tyszkiewicz E, Wilczynski GM, Lipp HP, Kaczmarek L, Filipkowski RK (2009) New hippocampal neurons are not obligatory for memory formation; cyclin D2 knockout mice with no adult brain neurogenesis show learning. Learn Mem 16:439-451.

Jessberger S, Clark RE, Broadbent NJ, Clemenson GD Jr, Consiglio A, Lie DC, Squire LR, Gage FH (2009) Dentate gyrus-specific knockdown of adult neurogenesis impairs spatial and object recognition memory in adult rats. Learn Mem 16:147-154.

Kempermann G, Kuhn HG, Gage FH (1997) Genetic influence on neuro- genesis in the dentate gyrus of adult mice. Proc Natl Acad Sci U S A 94:10409-10414.

Kenney AM, Widlund HR, Rowitch DH (2004) Hedgehog and PI-3 kinase signaling converge on $\mathrm{Nmycl}$ to promote cell cycle progression in cerebellar neuronal precursors. Development 131:217-228.

Kitamura T, Saitoh Y, Takashima N, Murayama A, Niibori Y, Ageta H, Sekiguchi M, Sugiyama H, Inokuchi K (2009) Adult neurogenesis modulates the hippocampus-dependent period of associative fear memory. Cell 139:814-827.

Kuo CT, Mirzadeh Z, Soriano-Navarro M, Rasin M, Wang D, Shen J, Sestan N, Garcia-Verdugo J, Alvarez-Buylla A, Jan LY, Jan YN (2006) Postnatal deletion of Numb/Numblike reveals repair and remodeling capacity in the subventricular neurogenic niche. Cell 127:1253-1264.

Lee JD, Ulevitch RJ, Han J (1995) Primary structure of BMK1: a new mammalian map kinase. Biochem Biophys Res Commun 213:715-724.

Leuner B, Gould E (2010) Structural plasticity and hippocampal function. Annu Rev Psychol 61:111-140, C1-C3.

Leuner B, Mendolia-Loffredo S, Kozorovitskiy Y, Samburg D, Gould E, Shors TJ (2004) Learning enhances the survival of new neurons beyond the time when the hippocampus is required for memory. J Neurosci 24:7477-7481.

Lie DC, Colamarino SA, Song HJ, Désiré L, Mira H, Consiglio A, Lein ES, Jessberger S, Lansford H, Dearie AR, Gage FH (2005) Wnt signalling regulates adult hippocampal neurogenesis. Nature 437:1370-1375.

Liu L, Cavanaugh JE, Wang Y, Sakagami H, Mao Z, Xia Z (2003) ERK5 activation of MEF2-mediated gene expression plays a critical role in BDNF-promoted survival of developing but not mature cortical neurons. Proc Natl Acad Sci U S A 100:8532-8537.

Liu L, Cundiff P, Abel G, Wang Y, Faigle R, Sakagami H, Xu M, Xia Z (2006) Extracellular signal-regulated kinase (ERK) 5 is necessary and sufficient to specify cortical neuronal fate. Proc Natl Acad Sci U S A 103:9697-9702.

Malberg JE, Eisch AJ, Nestler EJ, Duman RS (2000) Chronic antidepressant treatment increases neurogenesis in adult rat hippocampus. J Neurosci 20:9104-9110.

Meshi D, Drew MR, Saxe M, Ansorge MS, David D, Santarelli L, Malapani C, Moore H, Hen R (2006) Hippocampal neurogenesis is not required for behavioral effects of environmental enrichment. Nat Neurosci 9:729-731.

Ming GL, Song H (2005) Adult neurogenesis in the mammalian central nervous system. Annu Rev Neurosci 28:223-250.

Saxe MD, Battaglia F, Wang JW, Malleret G, David DJ, Monckton JE, Garcia AD, Sofroniew MV, Kandel ER, Santarelli L, Hen R, Drew MR (2006) Ablation of hippocampal neurogenesis impairs contextual fear conditioning and synaptic plasticity in the dentate gyrus. Proc Natl Acad Sci U S A 103:17501-17506.

Shalizi A, Lehtinen M, Gaudilliere B, Donovan N, Han J, Konishi Y, Bonni A (2003) Characterization of a neurotrophin signaling mechanism that mediates neuron survival in a temporally specific pattern. J Neurosci 23:7326-7336.

Shan Q, Chan GC, Storm DR (2008) Type 1 adenylyl cyclase is essential for maintenance of remote contextual fear memory. J Neurosci 28:12864-12867.

Shors TJ, Townsend DA, Zhao M, Kozorovitskiy Y, Gould E (2002) Neurogenesis may relate to some but not all types of hippocampal-dependent learning. Hippocampus 12:578-584.

Silva AJ, Stevens CF, Tonegawa S, Wang Y (1992) Deficient hippocampal long-term potentiation in alpha-calcium-calmodulin kinase II mutant mice. Science 257:201-206.

Suh H, Deng W, Gage FH (2009) Signaling in adult neurogenesis. Annu Rev Cell Dev Biol 25:253-275.

Taubenfeld SM, Wiig KA, Bear MF, Alberini CM (1999) A molecular correlate of memory and amnesia in the hippocampus. Nat Neurosci 2:309-310.

Wang X, Merritt AJ, Seyfried J, Guo C, Papadakis ES, Finegan KG, Kayahara M, Dixon J, Boot-Handford RP, Cartwright EJ, Mayer U, Tournier C (2005) Targeted deletion of mek 5 causes early embryonic death and defects in the extracellular signal-regulated kinase 5/myocyte enhancer factor 2 cell survival pathway. Mol Cell Biol 25:336-345.

Wang X, Finegan KG, Robinson AC, Knowles L, Khosravi-Far R, Hinchliffe KA, Boot-Handford RP, Tournier C (2006) Activation of extracellular signal-regulated protein kinase 5 downregulates FasL upon osmotic stress. Cell Death Differ 13:2099-2108. 
Wang Y, Su B, Xia Z (2006) Brain-derived neurotrophic factor activates ERK5 in cortical neurons via a Rap1-MEKK2 signaling cascade. J Biol Chem 281:35965-35974.

Watson FL, Heerssen HM, Bhattacharyya A, Klesse L, Lin MZ, Segal RA (2001) Neurotrophins use the Erk5 pathway to mediate a retrograde survival response. Nat Neurosci 4:981-988.

West MJ, Slomianka L, Gundersen HJ (1991) Unbiased stereological estimation of the total number of neurons in the subdivisions of the rat hippocampus using the optical fractionator. Anat Rec 231:482-497.

Wong ST, Athos J, Figueroa XA, Pineda VV, Schaefer ML, Chavkin CC, Muglia LJ, Storm DR (1999) Calcium-stimulated adenylyl cyclase activity is critical for hippocampus-dependent long-term memory and late phase LTP. Neuron 23:787-798.

Wu ZL, Thomas SA, Villacres EC, Xia Z, Simmons ML, Chavkin C, Palmiter RD,
Storm DR (1995) Altered behavior and long-term potentiation in type I adenylyl cyclase mutant mice. Proc Natl Acad Sci U S A 92:220-224.

Yin JC, Wallach JS, Del Vecchio M, Wilder EL, Zhou H, Quinn WG, Tully T (1994) Induction of a dominant negative CREB transgene specifically blocks long-term memory in Drosophila. Cell 79:49-58.

Zhang CL, Zou Y, He W, Gage FH, Evans RM (2008) A role for adult TLXpositive neural stem cells in learning and behaviour. Nature 451:10041007.

Zhang M, Moon C, Chan GC, Yang L, Zheng F, Conti AC, Muglia L, Muglia LJ, Storm DR, Wang H (2008) Ca-stimulated type 8 adenylyl cyclase is required for rapid acquisition of novel spatial information and for working/episodic-like memory. J Neurosci 28:4736-4744.

Zhou G, Bao ZQ, Dixon JE (1995) Components of a new human protein kinase signal transduction pathway. J Biol Chem 270:12665-12669. 